\title{
REVITALIZAÇÃO URBANA: CONSENSOS E CONFLITOS NO CENTRO HISTÓRICO DE SANTOS VISTOS A PARTIR DA MÍDIA LOCAL
}

\author{
Marcelo Burgos Pimentel dos Santos ${ }^{1}$, Lúcio Nagib Bittencourt ${ }^{2}$, Fernando Burgos Pimentel dos Santos ${ }^{3}$
}

RESUMO: As políticas públicas de recuperação de centros históricos tornaram-se bastante comuns em várias cidades do Brasil e do exterior. Ao adotá-las, os gestores públicos justificam sua opção por conta da necessidade de incremento do turismo e da recuperação de espaços públicos supostamente abandonados. A preservação cultural, nesse caso representada pela preocupação com a preservação do patrimônio histórico das cidades, é tratada como uma questão consensual. Entretanto, o presente artigo pretende questionar este suposto consenso, tanto no âmbito teórico, em que diversos autores vêm apontando falhas na concepção dos programas de "revitalização", quanto no prático, posto que movimentos sociais e de luta por moradia vêm travando diversos conflitos, procurando a efetivação de seus direitos. A cidade de Santos-SP, que vem desenvolvendo seu Plano de Revitalização do Centro Histórico, também conhecido como Alegra Centro, é utilizada como estudo de caso para o mapeamento dos atores sociais capazes de influenciar a agenda pública no sentido de legitimar e efetivar tais programas, por meio de análise de reportagens sobre o tema na mídia local. O objetivo deste trabalho é avaliar o papel do Jornal A Tribuna em relação à essa política e sua influência na construção de um consenso.

PALAVRAS -CHAVE: Revitalização, Santos, Centro Histórico, Políticas Públicas, Patrimônio Histórico Gentrificação

ABSTRACT: The public policies for recuperation of inner cities have became common place in several cities of Brazil and abroad. When adopting those policies, the public officers justify their option due to the need for increase of tourism and reoccupation of pretensely abandoned public areas. Cultural preservation, thereby represented by the concern regarding preservation of cities historic patrimony, is treated as a consensual issue. Nevertheless, this paper intends to question such argued consensus, both as far as theories are concerned, where several authors have presented flaws in the conception of "revitalization" programs, as well as in practical terms, since the social movements have presented several conflicts, claiming for effectiveness of their rights. The city of Santos-SP, that has been developing its own inner city revitalization program (Plano de Revitalização do Centro Histórico de Santos-SP), also known as "Alegra Centro", is taken as a case study to this paper, in order to map social actors

\footnotetext{
1 Bacharel em Ciências Sociais, Mestre em Ciência Política e Doutorando em Ciências Sociais pela PUC-SP e pesquisador do NEAMP (Núcleo de Estudos em Arte, Mídia e Política) na mesma Instituição. Endereço: Rua Monte Alegre, $9844^{\circ}$ andar - sala 4E-20 Perdizes - CEP 05014-901 São Paulo - SP - Brasil. marceloburgos@uol.com.br

2 Bacharel em Administração Publica pela Escola de Administração de Empresas de São Paulo da Fundação Getúlio Vargas. Endereço: Av. Nove de Julho, 2029 - 11ºndar Bela Vista - CEP 01313-902 São Paulo - SP - Brasil. lucio.bittencourt@gvmail.br

3 Mestrando em Administração Pública e Governo na Escola de Administração de Empresas de São Paulo da Fundação Getúlio Vargas. Endereço: Av. Nove de Julho, 2029 - 11 andar Bela Vista - CEP 01313-902 São Paulo - SP. fernando.burgos@fgv.br
} 
capable of influencing local agenda, helping to legitimate, effecting these kind of programs, through an analysis of the local media's coverage of the theme. This article aims to evaluate the A Tribuna Journal`s role related to this policy and its influence on the consensual construction.

KEYWORDS: Revitalization - Santos - Inner Cities - Media - Culture - Cultural Heritage - Gentrification 


\section{Introdução}

Este artigo se inclui no debate acerca dos conflitos e consensos que envolvem as políticas públicas de "revitalização” de centros urbanos. Além de se propor a uma breve análise do tema no âmbito global, utiliza-se a cidade de Santos-SP como estudo de caso.

Como meio para ilustrar tais questões, optou-se pela análise quantitativa dos atores sociais com voz na principal mídia local, o jornal A Tribuna, fazendo uso, para tanto, de sua versão disponível on-line (www.atribuna.com.br) como base de consulta. No mecanismo de busca presente na página da Internet, adotamos como palavra chave o nome do programa, "Alegra Centro", válida para todos os cadernos do jornal, até o ano de 2005. A partir dos resultados encontrados, construímos um banco de dados das reportagens, procurando, em seguida, analisar qualitativamente quem são as vozes “autorizadas” pela mídia como comentaristas deste processo de revitalização. Por fim, refletimos sobre o papel do aspecto de preservação do patrimônio histórico local situado no centro e sua relação com aqueles atores.

Nesse sentido, pretendemos discutir as possíveis conseqüências de uma política urbana cada vez mais freqüente no mundo, levantando suas contradições, bem como suas possíveis estratégias de legitimação, através do diálogo com autores de diversas áreas, quais sejam os enfoques político, urbanístico, midiático, histórico e cultural.

\section{As Políticas de Revitalização:}

1.1. O global - As políticas de revitalização no mundo e a gentrificação

As chamadas "políticas de revitalização” dos centros urbanos vêm se destacando como política pública comum a várias cidades ao redor do mundo, em que pesem as diferenças e especificidades entre elas. Dentro da questão do crescimento das aglomerações urbanas, principalmente - mas não só - nas grandes metrópoles, as cidades começam a voltar suas atenções ao que ficou conhecido como o seu "centro" ou inner cities (Smith, 1996), ignorando-se os deslocamentos dessa “centralidade” ao longo de sua expansão.

O que fazia do seu antigo centro um lugar especial da cidade era a força das atividades econômicas e a concentração de equipamentos de cultura e lazer. Era ali onde todos trabalhavam e demandavam espaços públicos para a convivência. Processos de 
deslocamentos de centralidades urbanas, no entanto, trouxeram um desnível relacionado com a oferta e demanda - referente ao valor da terra: enquanto cresceu a procura por áreas periféricas, principalmente por grupos sociais médios e ricos, migraram juntamente para essas áreas as principais redes de comércio e serviços, causando um esvaziamento, no centro, desses grupos.

A saída desses grupos, contudo, não significa a ausência completa de habitantes. Grupos mais pobres, de menor renda, e associados a setores específicos de trabalho - o comércio popular em São Paulo (Simões Jr., 1994), os trabalhadores do porto em Santos (Lanna, 1996), a pequena indústria de manufatura em Barcelona (Claver, 2006) -, permaneceram no local, em meio a ausência quase completa de investimentos, públicos ou privados. Surge, então, a imagem que será atacada por essas políticas públicas: a da degradação e do abandono da área central.

A simbologia utilizada coloca o espaço em questão, defendendo-se como necessária sua reapropriação, já que ele teria se tornado “infreqüentável” para os grupos que se distanciaram dos centros. O que se esquece, porém, é que o centro sempre foi habitado, ainda que por outros grupos sociais; é dizer: o problema é a degradação do espaço urbano, e não a situação social das pessoas que habitam aquele espaço, como sugere Smith (1996), sobre as políticas de “revitalização”:

It focuses on 'making cities livable', meaning livable for the middle class. In fact, and of necessity, they have always been 'livable' for the working class. The so-called renaissance is advertised and sold as bringing benefits to everyone regardless of class, but available evidence suggests otherwise (Smith, 1996, p.89).

Esse movimento de volta ao centro das cidades - por meio de políticas públicas e capital privado - utiliza como estratégia o conceito de gentrificação. Apesar de assumir diferentes especificidades na Europa, nos Estados Unidos ou na América Latina (Bidou-Zachariasen, 2006), esse conceito norteia a idéia comum de “revitalização”, muito relacionada com o modelo de desenvolvimento de Michael Porter, baseado no fortalecimento de atividades lucrativas, configurando os centros históricos como “espaços competitivos” (Hiernaux-Nicolas, 2006“ii. Porter, 1995). Dentro dessa perspectiva, o resultado, visto como positivo pelos idealizadores dessa política, é bem descrito por Francisco de Oliveira (2002): 
Tiraram-se os pobres, mendigos, prostitutas, bares de má-fama com seus rufiões, botecos sujos e tristes, pensões baratas com suas fileiras de redes, substituídos por maquiagens do que se considera, então, 'os velhos bons tempos'. Esvazia-se a história de quem viveu lá; em lugar da memória, o esquecimento. Trata-se de operações de elevação da renda da terra urbana, vale dizer, de uma acumulação primitiva pela via do investimento público. Outra vez, privatizou-se o público, mas não se publicizou o privado: sobe a renda da terra e a parcela dos novos proprietários no excedente social, e decresce a parcela de todos os 'sem'. Nenhum critério que publicize o lucro, no sentido de introduzir nele o conflito. A justificativa está sempre à mão: novos empregos, aumento da renda, da segurança, da convivialidade. Entre iguais. E distância dos desiguais (Oliveira, 2000, p. 24).

Esse excerto traz importantes referências. O investimento público é importante parceiro do capital privado nesses processos de reinvestimento, como em Barcelona, centrandose na oferta de equipamentos culturais (Claver, 2006). A construção da memória e identidade local estará freqüentemente em disputa nessas políticas, por meio da atenção especial aos imóveis protegidos como patrimônio histórico, como em Nápoles (Cattedra e Memolli, 2006) ${ }^{\mathrm{iii}}$. Por fim, traz consigo a exclusão de segmentos específicos da sociedade, já, em geral, marginalizados. Assim:

A gentrificação é um fenômeno ao mesmo tempo físico, econômico, social e cultural. Ela implica não apenas uma mudança social, mas também uma mudança física do estoque de moradias na escala de bairros; enfim, uma mudança econômica sobre os mercados fundiário e imobiliário. É esta combinação de mudanças sociais, físicas e econômicas que distingue a gentrificação como um processo ou conjunto de processos específicos (Bidou-Zachariasen, 2006, p.23).

A busca da transformação do centro histórico de Santos irá refletir vários desses conceitos "globais” referentes à "revitalização" do espaço urbano.

\subsection{O local - A "Revitalização" em Santos}

Desde a década de 1980, o centro de Santos vem se configurando como espaço de interesse da administração pública local ${ }^{\text {iv }}$ É após a eleição de Beto Mansur como prefeito municipal, em 1997, contudo, que as ações ganham maior força: a parceria com o governo do Estado permitiu o início de intervenções em edificações simbólicas para a cidade como a Estação Ferroviária do Valongo, os teatros Coliseu e Guarany (ainda não concluído) e a Bolsa do Café. Além disso, houve, ainda, a reativação de uma linha de 
bonde, de caráter turístico, passando por ruas que haviam sido restauradas, o que gerou um grande interesse por parte da imprensa e também de santistas e turistas.

Mas é no final de seu primeiro mandato e já eleito para o segundo (2001-2004), que o prefeito Beto Mansur começa a articular um programa específico para o centro: o Alegra Centro. Liderado pelo então vice-prefeito eleito João Paulo Tavares Papa, propôs-se a recriação da Secretaria do Planejamento - extinta em gestões anteriores -, para que esta instância municipal conduzisse um plano de revitalização da região, calcado em incentivos fiscais e no estabelecimento de diretrizes urbanísticas.

A concepção inicial do projeto teve Barcelona, Recife e Rio de Janeiro como maiores referências, mas também inspirou-se nas revitalizações de Belém e Buenos Aires, principalmente no que tange à projetos do tipo waterfront - isto é, que prevêem a utilização de áreas portuárias ociosas para lazer. Após algumas alterações sugeridas por conselhos municipais e outras secretarias da prefeitura, surge o Programa de Revitalização e Desenvolvimento da Região Central Histórica de Santos - LC 470/03, também conhecido como “Alegra Centro”.

Em 2001, já tinha sido aprovada a LC 448/01, que criou as Áreas de Proteção Cultural (APCs). Essa lei impõe maiores restrições a utilizações dos imóveis do centro, impedindo, por vezes, modificações internas e externas, assim como a conservação das fachadas, da volumetria e do telhado. Ela prevê, também, benefícios fiscais em troca da preservação ou restauração desses imóveis.

O Alegra Centro gera uma expectativa muito grande na cidade, uma vez que além do caráter econômico e turístico, traz um componente de resgate da identidade local. A mídia estimula essa percepção em relação ao programa e faz com que as atenções da população estejam voltadas à ação da prefeitura e também sobre as negociações que ocorreram na Câmara de Vereadores, até a aprovação do texto final em 2003.

O programa torna-se inclusive uma das bandeiras eleitorais do vice-prefeito João Paulo Tavares Papa (PMDB) na disputa municipal de 2004. Apoiado pelo prefeito Beto Mansur (PP), Papa vence a ex-prefeita Telma de Souza (PT) e promete melhorar o programa, cujos resultados estavam abaixo do esperado e também prometido pela gestão anterior. 
Em março de 2005, o Executivo municipal realizou algumas alterações para “aperfeiçoar” a legislação existente do Alegra Centro. A LC 526/05 modifica, basicamente, dois quesitos tributários referentes a isenção de impostos. Dessa maneira, fica evidente que o projeto de “revitalização” do centro de Santos baseia-se na visão de que o poder público deve ser o responsável pela criação de condições capazes de atrair o investimento privado. É esse o teor do plano de intervenção nesse espaço urbano.

\section{O Centro Histórico como palco de conflitos}

2.1. As transformações do “Centro” ao longo da história

Apesar de fundada no ano de 1532, é apenas na segunda metade do século XIX que Santos começará a crescer e preencher um lugar de relevância no plano nacional. Essa transformação estará intimamente ligada à expansão da cultura do café no Estado de São Paulo, à construção da linha ferroviária que ligava quase toda a produção do Estado a Santos e a expansão de seu porto, necessária para se adaptar à nova demanda. Como resultado, já no início do século XX, o porto de Santos é responsável pela exportação de cerca de dois terços de toda a produção nacional de café (Gitahy, 1986).

As mudanças que a cidade irá enfrentar naquele início de século, então, serão bastante significativas para seu futuro. A incorporação de milhares de imigrantes europeus na força de trabalho portuária, a consolidação da elite local com base no comércio - em especial na exportação - do café, o pequeno comércio sob propriedade dos portugueses, serão algumas das características que irão influenciar as questões políticas locais (Lanna, 1996).

Quando levamos em consideração que, no início do Novecentos, a cidade se concentrava na região que hoje se denomina Centro, começam a surgir novos aspectos relevantes. $\mathrm{O}$ adensamento populacional será bastante acentuado na cidade:

Em 1889 a cidade tinha (...) aproximadamente 15.600 habitantes e 2.000 casas. $O$ aspecto geral era horrível. Nos dias de chuva, as ruas sem calçamento transformavam-se em lagos. As casas estavam sendo rapidamente transformadas em cortiços "para abrigar imigrantes que chegavam para trabalhar nas obras do porto” (Lanna, 1996, p. 70).

Ao mesmo tempo, "uma estatística municipal constata a existência de 771 cortiços, dos quais 478 considerados em mau estado, no ano de 1891” (Gitahy, 1986, p. 70). Essa 
situação se acentuará, ainda, com o agravamento de epidemias que irão dizimar milhares de cidadãos, bem como justificar a intervenção de outras esferas de governo no âmbito municipal, uma vez que esses fatos poderiam comprometer o bom funcionamento da economia baseada na exportação de café.

Dessa maneira, a crise provocada pelo surto de crescimento que acometeu a cidade no final do século XIX e início do XX terá como resposta uma "política de intervenção urbana com forte cunho sanitarista e que acabava por excluir a população pobre” (Lanna, 1996, p. 72) - o que irá lembrar a semelhante intervenção que sofreu o Rio de Janeiro no mesmo período (Chalhoub, 1996).

Vale lembrar que, nessa mesma época, o movimento operário e sindicalista, em Santos, ganhava força e começava a se organizar, publicar seus próprios periódicos e promover as primeiras greves no porto (Gitahy, 1986). O que significa dizer que a remodelação urbana do Centro de Santos, não foi feita sem o enfrentamento de um conflito. Para superá-lo, foi necessária a criação de um consenso com base na "higiene como ideologia” (Chalhoub, 1990, p.13), justificada pela “imperiosidade do progresso" (Lanna, 1996, p.79) e pelo saber científico, capaz de legitimar "uma política repressiva e destruidora de formas de vida e associação sobretudo das classes trabalhadoras” (Lanna, 1996, p.79). A saúde da cidade, portanto, era o bem coletivo que se objetivava, pelo qual, teria que se aceitar as conseqüências.

Apesar de todo o investimento que foi destinado ao Centro: a demolição de cortiços, a abertura de novas ruas e a construção de praças e equipamentos de cultura e lazer voltados para as elites locais, o decorrer do século XX viu nova transformação da região. O crescimento e desenvolvimento de outras áreas da cidade provocaram um deslocamento de centralidade (Melé, 2006)ำ: novos núcleos comerciais, a diversificação no trabalho voltada para o setor de serviços e a ocupação e valorização da região das praias, concentraram os investimentos em outras localidades. A proibição do uso do Centro para moradia, nos anos 60 - por meio da Lei Complementar 3529/68, que instituiu um Plano Diretor no município -, também colaborou nesse sentido, favorecendo o predomínio da população mais pobre no local, retratada, novamente, pelos cortiços. 
2.2. Os planos de revitalização urbana do fim do século XX

Essa nova face do Centro, pobre, abandonado, degradado e perigoso, é que vai justificar uma nova intervenção urbanística, agora chamada de “revitalização”. É interessante notar, contudo, que a imagem do "centro degradado" já se trata, em si, de uma construção. Afinal, apesar dos problemas causados pelo deslocamento de centralidade, a região central nunca foi verdadeiramente “abandonada”, senão prosseguiu como centro político - já que as instituições públicas permaneceram - e com relevância na economia da cidade devido ao comércio popular e ao setor de serviços portuários.

Conforme vimos, as políticas de "revitalização" vêm acompanhadas do fenômeno da gentrificação. Apesar de possuir diferentes peculiaridades, que variam de caso a caso, o conceito traz a idéia de atrair o capital às áreas da cidade que se encontram desvalorizadas. A infra-estrutura urbana que os centros possuem traz a possibilidade de grandes ganhos nesse reinvestimento, o rent gap (Smith, 1996).

Os resultados de políticas desse tipo também variam. Pode-se dizer que a população pobre que habita essas regiões desvalorizadas corre fortes riscos de ser expulsa, caso a política seja efetivada. A alteração dos equipamentos à disposição, bem como dos espaços públicos, acaba atraindo grupos mais ricos para essa região, bem como novos investimentos voltados a esses grupos.

\subsection{Os cortiços}

No caso de Santos, a política de revitalização acabou fortalecendo a organização dos moradores de cortiços do centro. A ACC - Associação dos Cortiços do Centro ganhou notoriedade enquanto movimento social que busca a efetivação de direitos e a participação nas políticas públicas que, mais uma vez, “os afeta, mas não os inclui” (Lanna, 1996, p.83). É possível citar a moradia popular, a geração de emprego e renda e o acesso a equipamentos públicos de cultura e lazer como algumas das principais demandas desse grupo que foi capaz de, ao mesmo tempo, unir outras instituições organizações não-governamentais - na mesma luta por sobrevivência no espaço do Centro. 
Em que pese os objetivos conflitantes, não se pode dizer que há completa ausência de diálogo entre os promotores da política pública e os moradores de cortiço. O que é oferecido a eles, contudo, parece muito mais fazer parte de um discurso - como em Nápoles (Cattedra e Memoli, 2006) e Barcelona (Claver, 2006) - do que de uma prática. Apesar do plano de revitalização do Centro de Santos incluir a questão das moradias populares, por meio do Programa de Atuação em Cortiços (PAC) do governo do Estado de São Paulo, a oferta de 194 apartamentos que serão construídos ${ }^{\mathrm{vi}}$, no entanto, é muito aquém da demanda (14.500 moradores). É interessante notar que nessa questão habitacional, a responsabilidade pela solução da questão foi transferida para um órgão do governo estadual. Além disso, o novo comércio que a "revitalização" atraiu, ou os equipamentos públicos que restaurou, não servem aos moradores de cortiços, que não dispõem de renda para freqüentá-los ou de políticas que os inclua.

Assim, com um conflito latente na região do Centro, a política pública, para prevalecer, precisou - e ainda o faz - buscar justificativas para a intervenção urbana. A construção desse consenso em torno da importância de se "revitalizar" o Centro fará uso de diversos artifícios, como o arranjo com a mídia local, a construção de uma memória histórica - que faz referência às transformações do início do século passado - e o discurso do "bem coletivo".

\section{A mídia e a construção do consenso}

Nesta parte, procuramos analisar a atuação da imprensa escrita de Santos em situações políticas geradoras de notícias que, por sua vez, também se constituem em conjunturas políticas abertas à interferência no jogo pelo equilíbrio-desequilíbrio das forças sociais envolvidas no conflito de geração de notícias. Nestas situações verificam-se diferentes tipos de embates políticos, entre os quais aquele que se dá entre mídia e poder local - um, buscando interferir sobre o outro, ou em outras palavras, na tentativa de pautar a agenda política. Através desta pesquisa, pretende-se compreender os mecanismos de influência e de pressão que ocorreram para tentar formar um consenso sobre o Alegra Centro, bem como entender como se deu a construção da agenda para esse tema, encarando como relevante apenas alguns itens importantes - como o atração de novos empreendimentos para o centro, e ignorando outros - como a questão dos moradores de cortiços. 
Para Cobb e Elder (1995) há dois tipos básicos de agendas políticas. A primeira delas se refere à todas as questões percebidas pela comunidade política como merecedora de atenção pública e envolvidas com problemas em que haja a existência de uma autoridade governamental legítima. O segundo tipo de agenda é a institucional, governamental ou agenda formal, ou seja, aquelas que são consideradas seriamente pelos tomadores de decisão. Segundo os autores, para que uma questão receba o reconhecimento popular, é necessário que uma grande quantidade de pessoas reconheça a necessidade de uma ação de remediação e requeira esse tipo de ação. Ou seja, essa ação deve ser considerada não somente possível, mas também necessária para a resolução desse problema. Segundo eles, um outro papel fundamental é desempenhado pela mídia; neste caso específico, o Grupo A Tribuna de Comunicação:

The media can also play a very important role in elevating issues to the systemic agenda and increasing their chances of receiving formal agenda consideration. Certain personages in the media can act as opinion leaders in bringing publicity to a particular issue. (COBB \& ELDER, 1995, p. 103)

Kingdon (1995) afirma que processo decisório de uma política pública envolve basicamente duas questões: onde surgiu a demanda e quem participará do processo de definição da agenda. Fuks (2000) aponta duas questões básicas para a análise da agenda. A primeira é o modo como surgem os assuntos e por que alguns destes se tornam prioridade e outros não. $\mathrm{O}$ segundo está relacionado a quais atores efetivamente participam da definição de assuntos públicos. Os meios de comunicação de massa são apontados como uma arena estratégica, uma vez que articula as demais arenas. Eles influenciam a definição das agendas societal e governamental, mas também sugerem o “como pensar”. E, nesse item, é interessante observar com o Grupo A Tribuna conduziu a discussão.

Em relação à segunda questão descrita por Fuks (2000), relativa ao conjunto de atores que participam das decisões, ele pode ser composto por especialistas em determinadas áreas temáticas ou até mesmo, de um espaço social mais amplo, em que os movimentos sociais poderiam atuar. $\mathrm{O}$ autor reconhece que alguns atores podem levar claras vantagens (de recursos materiais, organizacionais e simbólicos) sobre outros.

Assim, enquanto Fuks (2000) considera os diversos grupos de pressão como em constante disputa por um lugar de destaque para as suas questões no maior número de arenas possível, 
Kingdon (1995) define os atores invisíveis como sendo os técnicos que formulam as políticas, os assessores parlamentares, os acadêmicos, sendo que estes afetam menos a agenda e mais as alternativas de políticas. Assim, a formulação e a execução das políticas seriam questões técnicas, separadas da política.

Para Kingdon (1995), um outro ator é a mídia que poderia ajudar a ampliar os conflitos e até mesmo mudar o rumo de algumas questões, afetando a opinião pública e também as alternativas que estão sendo propostas pelos demais atores. No presente momento o jornal A Tribuna de Santos, que faz parte do Sistema A Tribuna de Comunicações, se constitui numa das principais fontes formadoras da opinião pública da Cidade - talvez a maior, e é o principal jornal diário da cidade há muito tempo. Ademais, com o surgimento das propriedades cruzadas dos meios de comunicação, aliou-se às Organizações Globo e também possui a emissora afiliada a Rede Globo na região da Baixada Santista e Litoral Sul do estado de São Paulo. Ou seja, este veículo comporta-se como fonte principal da formação da opinião pública local como veremos adiante.

Bagdikian (1993) mostra que a mídia atual passa a ser controlada por várias corporações multinacionais, e o mesmo ocorre em Santos. Segundo o autor, estas acabam controlando não apenas um setor midiático, mas vários, englobando sistemas de telefonia, satélites, radiodifusão, revistas, jornais, televisão, cinemas etc., numa complexa rede de relações e sistemas de poder. Sem o apoio da Globo, A Tribuna já era proprietária de rádio, jornal e gráfica. Com os direitos de transmissão da programação da Rede Globo passa a dominar mais um meio de comunicação importantíssimo, a televisão. Depois passou a servir de provedora de acesso à Internet ocupando, dessa forma, todos ou quase todos os espaços que uma empresa de comunicação pode atuar.

A liderança do Sistema A Tribuna de Comunicações parece ser permanente pois em pesquisa IBOPE (Santos, 2003), A Tribuna apareceu como o jornal mais lido na Baixada Santista com um número de leitor diário situado por volta de 435 mil pessoas, e com $80 \%$ do consumo de jornais nessa região. Em segundo lugar, apareceu a Folha de São Paulo com um público de 74 mil leitores e 14\% do consumo de jornais. E, em terceiro lugar, apareceu O Estado de São Paulo com cerca de 63 mil leitores e 12\% do consumo. Através desses números pode ser percebida a esmagadora presença de A Tribuna como fonte formadora da 
opinião pública na Baixada Santista. Também é constatado que um pequeno número de leitores têm acesso a mais de um jornal ${ }^{\text {vii }}$.

Um outra abordagem é a definição, já clássica, do conceito de agendamento ou agenda setting que diz que a mídia não consegue dizer às pessoas como pensar, mas tem capacidade de dizer sobre o que pensar, ou seja, há uma capacidade da mídia definir os temas ou assuntos que serão comentados, discutidos pela população a partir da sua própria exposição ou exibição pública (Wolf, 1987; Traquina, 2001). Ou seja, a partir daquilo que entrou ou não em discussão pública, via mídia, compreende-se os assuntos que são ou deixam de ser discutidos.

Estes mesmos autores, acima destacados, discutem também o mecanismo de newsmaking, que demonstra a capacidade que a mídia tem de fazer as notícias, ou seja, a capacidade de dizer o que vai ser ou não pautado nas suas coberturas. É justamente este sobre o que pensar, que iremos analisar o conteúdo da mídia e o seu papel em Santos.

No caso, observado percebe-se que a discussão sobre o Alegra Centro foi coberto pela mídia e, dessa forma, foi discutido publicamente. Agora, também percebe-se que o assunto foi discutido sem levar em consideração as pessoas que habitam a região central da cidade, uma vez que elas quase não apareceram na cobertura midiática, permanecendo invisíveis no que podemos denominar de critério de noticiabilidade.

O debate político na atualidade é realizado, apoiado ou, pelo menos, pontuado pela mídia. Se a questão não está na mídia, dificilmente é levada em consideração. Ser, hoje em dia, é, antes de tudo, ser na mídia. Se você não é na mídia também não será em nenhum outro lugar. Ou seja, a mídia tem a capacidade de fazer você ser percebido ou fornece às pessoas a capacidade de existir, uma vez que ser, fora da mídia, é quase um sinônimo de não existir. Como veremos, algumas vozes foram completamente alijadas no processo de discussão sobre a revitalização do Centro histórico de Santos. Ou seja, é como se elas não existissem.

De acordo com Bourdieu (1997), os jornalistas têm “óculos” especiais a partir dos quais vêem certas coisas e não outras; e vêem de certa maneira as coisas que vêem. Eles operam uma seleção e uma construção do que é selecionado.

Outra idéia que utilizamos é de framing ou enquadramento, utilizada por Porto (1999) e que auxilia na compreensão da abordagem que o jornal faz de suas matérias, idéias e concepções. 
Esta abordagem já foi utilizada pelo próprio Mauro Porto, Aldé e Lattman-Weltman ${ }^{\text {viii }}$, entre outros pesquisadores. Esse conceito está baseado na forma como as políticas públicas e as notícias são cobertas no jornal e serviu de base e fundamento para o nosso entendimento da cobertura dos noticiários sobre o Alegra Centro.

A questão dos óculos especiais a que se refere Bourdieu (1997) possui a mesma problemática que também é trabalhada por Traquina (2001), sob o nome de gatekeeper, ou seja, a notícia tem que possuir uma série de pré-requisitos antes de ser levada ao ar ou ser publicada. Diz este autor:

Em 1950, a publicação de um artigo na revista acadêmica mais antiga desta área científica, Journalism Quarterly, iria construir um marco histórico no estudo do jornalismo. No seu artigo, David Manning White, aplica o conceito de gatekeeper ao jornalismo, originando assim uma das tradições mais persistentes e prolíferas na pesquisa sobre as notícias. Na teoria de White, o processo de produção das notícias é concebido como uma série de escolhas, onde um fluxo de notícias tem de passar por diversos 'portões' (os famosos gates), que são momentos de decisão em relação aos quais o gatekeeper (o jornalista) tem de decidir se vai escolher ou não essa notícia, deixá-la passar ou não. O conceito de gatekeeper seria altamente influente numa fase do estudo do jornalismo que cobre as décadas de 50 e 60 (...) e continua nos anos 90 a alimentar todo um filão de investigação, embora sem a hegemonia que conseguiu em tempos passados (Traquina, 2001, p.54).

Dessa forma, os editores podem eleger o que é ou não noticiável, de acordo com seus próprios interesses ou o interesse da empresa par ao qual trabalham. No entanto, os estudos de recepção indicam a possibilidade do gatekeeper ser menos hegemônica do que se supões, uma vez que sempre existe uma reação ou um contra-fluxo daquilo que é produzido no jornalismo $^{\mathrm{ix}}$. As pessoas, em geral, têm capacidade de distinguir as abordagens e enfoques midiáticos de acordo com suas percepções subjetivas, o que nem sempre é uma tarefa fácil.

Bourdieu (1997) trabalha com o conceito de homogeneização das informações ou notícias, ou seja, aquilo que é transmitido ou noticiado em determinado telejornal ou jornal também terá que ser coberto pelos demais, sob o risco destes ficarem sem o chamado "furo". A isto, o autor denomina “circulação circular da informação”. Diz ele:

As escolhas que se produzem na televisão são de alguma maneira escolhas sem sujeito. Para explicar essa proposição talvez um pouco excessiva, invocarei simplesmente os efeitos do mecanismo de circulação circular a que aludi 
rapidamente: o fato de os jornalistas, que, de resto, têm muitas propriedades comuns, de condição, mas também de origem e de formação, lerem-se uns aos outros, verem-se uns aos outros, encontrarem-se constantemente uns com os outros nos debates em que se revêem sempre os mesmos, tem efeitos de fechamentos e, não se deve hesitar em dizê-lo, de censura tão eficazes - mais eficazes mesmo, porque seu princípio é mais invisível - quanto os de uma burocracia central, de uma intervenção política expressa (Bourdieu, 1997, p.34-5).

Ou seja, o que uma mídia diz, seus pares terão que dizer ou, mais ainda, as outras mídias também terão que informá-lo. No caso de Santos, aquilo que é noticiado pela principal empresa midiática local também repercute nas suas concorrentes.

Outro aspecto importante da teoria que trata das pautas do jornalismo diz respeito ao que pode ser noticiável, porque nem tudo que chega às redações é publicado ou veiculado. Tudo depende de uma série de fatores que vão desde a relevância do acontecimento, passando por interesses dentro das redações - aqui o critério pode ser mais subjetivo ou mesmo sujeito a interesses econômicos, por exemplo - até chegar o momento da construção das notícias, que Traquina (2001), dialogando com Wolf (1987) retrata da seguinte forma:

As notícias são o resultado de um processo de produção definido como a percepção, seleção e transformação de uma matéria-prima (principalmente os acontecimentos) num produto (as notícias). Os acontecimentos constituem um imenso universo de matéria-prima; a estratificação deste recurso consiste na seleção do que irá ser tratado, ou seja, na escolha do que se julga ser matéria prima digna de adquirir a existência pública de notícia, numa palavra - ter noticiabilidade (newsworthiness). Aliás, a questão central do campo jornalístico é precisamente esta: o que é notícia?, ou seja, quais os critérios e os factores [sic] que determinam a noticiabilidade dos acontecimentos (Traquina, 2001, p.94).

Para Bagdikian (1993), a utilização técnica da TV, do cinema e do rádio misturam normas, símbolos, mitos e imagens, atingindo, inclusive, a intimidade dos indivíduos, cujo comportamento passa a ser ditado pelos meios de comunicação, estruturado nos instintos que orientam uma nova forma e estilo de viver. Assim, a sociedade sofre o jogo pelo controle, por parte das corporações, através da projeção e identificação de desejos, identificados por uma nova classe consumidora e representativa da sociedade de massas.

Como conseqüência, a mídia passa a ter um interesse maior em proteger seus interesses de mercado, corporativos, do que em informar com isenção total o seu público. Ou seja, se o 
interesse das corporações for contrário à atitude política, econômica, social ou qualquer que seja, esta fará de tudo para impedir a sua realização, gerando, dessa maneira, uma maior dificuldade do leitor em entender o verdadeiro cenário da política ${ }^{\mathrm{x}}$.

O que tentamos desenvolver ao longo deste artigo é a mensuração da influência da mídia na formação de consenso e valores para os cidadãos santistas. Não trabalharemos com a idéia de que a mídia manipula as pessoas pois, se partirmos deste pressuposto é como se as pessoas que consomem a mídia não são dotadas de vida inteligente porque se comportam da mesma maneira frente a um estímulo, não reinterpretando esses dados ou fontes de informação. Preferimos trabalhar com a idéia de influência.

Em Santos, a situação fica ainda mais crítica e delicada, pois conforme já mencionado, é basicamente um único grupo que faz a representação, projeção e identificação dos desejos coletivos, de acordo com seus interesses. Ainda de acordo com Bagdikian (1993), esta situação é semelhante ao que acontece e aconteceu com as cidades americanas que, paulatinamente, foram perdendo espaço de discussão e apresentação de idéias antagônicas.

Quando uma empresa passa a dominar o mercado de mídia, a sua primeira intenção, como em qualquer outro negócio, é obter lucro; o segundo e, não menos importante, é a capacidade de influenciar opiniões. Bagdikian afirma:

Influência: as corporações que 'dominam o mercado' na mídia de massa influenciam de forma preponderante as notícias que o público recebe, a informação, as idéias das pessoas, a cultura popular e as posturas políticas. Essas mesmas corporações exercem influência considerável dentro do governo, exatamente porque detêm o poder de influenciar a percepção que suas audiências têm acerca da vida pública, incluindo aquelas acerca da política e dos políticos, com base no modo como são divulgados - ou não - através da mídia (Bagdikian, 1993, p.25-6).

E aqui, é importante frisar que $A$ Tribuna está, ainda, de acordo com a tendência de concentração de meios de comunicação por uma família, assim como todos os demais grupos comunicacionais do Estado de São Paulo e, mesmo, do Brasil ${ }^{\mathrm{xi}}$. Nessa linha de raciocínio, além do lucro, a empresa também quer influenciar opinião, abordando através de suas reportagens e matérias aquilo que vale a pena ser publicado, discutido e mais importante, com o enquadramento (ou enfoque) que lhe interessa. 


\subsection{Análise: Os Atores e a mídia local}

O total de matérias com identificação de discursos de atores - diretos ou indiretos - foi de 145 ocorrências - de 2\%/2000 a 2\%/2005. Em caso de matérias com temas diversos, concentrava-se o registro somente nos discursos pertinentes ao Alegra Centro ou assuntos relacionados ao programa. Algumas matérias que não apresentavam discurso de atores foram descartadas.

O primeiro trabalho - e que servirá de base para todos os resultados encontrados - foi criar um mini banco de dados, com algumas informações sobre as 145 reportagens. Na Tabela 1, temos a distribuição dessas reportagens, de acordo com o semestre e o ano:

Tabela 1: Número de ocorrências por período

\begin{tabular}{|c|c|}
\hline Período & Alegra Centro \\
\hline $2^{\circ}$ semestre / 2000 & 1 \\
\hline $1^{\circ}$ semestre / 2001 & 1 \\
\hline $2^{\circ}$ semestre / 2001 & 4 \\
\hline $1^{\circ}$ semestre / 2002 & 8 \\
\hline $2^{\circ}$ semestre / 2002 & 75 \\
\hline $1^{\circ}$ semestre / 2003 & 27 \\
\hline $2^{\circ}$ semestre / 2003 & 9 \\
\hline $1^{\circ}$ semestre / 2004 & 8 \\
\hline $2^{\circ}$ semestre / 2004 & 4 \\
\hline $1^{\circ}$ semestre / 2005 & 7 \\
\hline $2^{\circ}$ semestre / 2005 & 1 \\
\hline TOTAL & 145 \\
\hline
\end{tabular}

Fonte: pesquisa dos autores

Pode-se notar claramente um predomínio muito grande do tema no $2^{\circ}$ Semestre de 2002. Esse foi o período em que o projeto tramitou pela Câmara Municipal de Santos. Como esse foi um processo bastante controvertido, em virtude de interesses políticos dos vereadores, era comum o tema aparecer em reportagens locais. 
Essa tramitação, que demorou mais que um ano, trouxe resultados para este artigo, conforme podemos notar na segunda tabela que identifica os atores mais freqüentes na formação do discurso sobre o Programa Alegra Centro.

É importante verificar que os totais de matérias e ocorrências não são coincidentes pois em uma matéria é possível - e freqüentemente isso ocorreu - que haja mais de um ator se posicionando. O principal entrevistado foi o ex-Secretário de Planejamento e VicePrefeito de Santos, João Paulo Tavares Papa, que foi um dos formuladores do projeto de lei. Papa apareceu em 43 ocasiões, sendo seguido por uma série de vereadores. É importante notar que após os vereadores há dois personagens importantes: Marcio Lara e Beto Mansur. O primeiro era o chefe de gabinete da Secretaria de Planejamento e esteve diretamente envolvido na formulação do Alegra Centro. O segundo é o exprefeito de Santos (1997-2004), que cumpria o seu segundo mandato, nesse período de aprovação do projeto de recuperação do Centro Histórico de Santos.

Observando a Tabela 2, é possível notar que além dos atores, algumas entidades foram agrupadas, de forma a facilitar as análises posteriores.

Tabela 2: Relação de Atores e número de entrevistas

\begin{tabular}{|l|l|c|c|}
\hline \multicolumn{1}{|c|}{ Ator } & \multicolumn{1}{c|}{ Entidade } & Total & $\begin{array}{c}\% \text { do } \\
\text { Total }\end{array}$ \\
\hline João Paulo Tavares Papa & Prefeitura & 43 & $15,69 \%$ \\
\hline Mantovani Calejon (PPB) & Vereador & 28 & $10,22 \%$ \\
\hline José Antônio M. Almeida - Jama (PPS) & Vereador & 19 & $6,93 \%$ \\
\hline Adelino Rodrigues (PSB) & Vereador & 12 & $4,38 \%$ \\
\hline Cassandra Maroni (PT) & Vereador & 12 & $4,38 \%$ \\
\hline Carlos Eduardo Adegas (PL) & Vereador & 9 & $3,28 \%$ \\
\hline Márcio Lara & Prefeitura & 8 & $2,92 \%$ \\
\hline Odair Gonzalez (PPB) & Vereador & 7 & $2,52 \%$ \\
\hline Beto Mansur (PPB) & Prefeitura & 7 & $2,55 \%$ \\
\hline Suely Morgado (PT) & Vereador & 6 & $2,19 \%$ \\
\hline Fausto Lopes (PFL) & Vereador & 6 & $2,19 \%$ \\
\hline Pedro Mahfuz Júnior & CDL + ACS + SCVS & 5 & $1,82 \%$ \\
\hline Amadeu Lopes Lousada & CDL + ACS + SCVS & & \\
\hline
\end{tabular}




\begin{tabular}{|c|c|c|c|}
\hline Geonísio Aguiar (sem partido) & Vereador & 5 & $1,82 \%$ \\
\hline Manoel Constantino (PMDB) & Vereador & 5 & $1,82 \%$ \\
\hline Nobel Soares & Advogado & 4 & $1,46 \%$ \\
\hline Antonio Carlos Gonçalves & Prefeitura & 3 & $1,09 \%$ \\
\hline Débora Blanco & Prefeitura & 3 & $1,09 \%$ \\
\hline Eduardo Carvalhaes Júnior & Associação Centro Vivo & 3 & $1,09 \%$ \\
\hline Fernando Vianna & Codesp & 3 & $1,09 \%$ \\
\hline Luiz Dias Guimarães & Prefeitura & 3 & $1,09 \%$ \\
\hline Paulo Barbosa & Vereador & 3 & $1,09 \%$ \\
\hline Antonio C. Banha Joaquim & Vereador & 2 & $0,73 \%$ \\
\hline Assesoria de Imprensa da Seplan & Prefeitura & 2 & $0,73 \%$ \\
\hline Assessoria de Imprensa da Codesp & Codesp & 2 & $0,73 \%$ \\
\hline Claudio Abdalla & Arquiteto & 2 & $0,73 \%$ \\
\hline Cláudio Ciorlia Denipoti & Empresariado - Outros & 2 & $0,73 \%$ \\
\hline Daury de Paula Júnior & Ministério Público & 2 & $0,73 \%$ \\
\hline José Lascane (PSDB) & Vereador & 2 & $0,73 \%$ \\
\hline Júlio Eduardo dos Santos & Prefeitura & 2 & $0,73 \%$ \\
\hline Luiz Carlos Santini Mello & Prefeitura & 2 & $0,73 \%$ \\
\hline Marinaldo Mongon (PTB) & Vereador & 2 & $0,73 \%$ \\
\hline Ney Caldato & Arquiteto & 2 & $0,73 \%$ \\
\hline Odete Ferreira de Lima & Empresariado-Comércio & 2 & $0,73 \%$ \\
\hline Professor Fabião (PSB) & Vereador & 2 & $0,73 \%$ \\
\hline Seplan - sem interlocutor & Prefeitura & 2 & $0,73 \%$ \\
\hline Tom Barboza & Prefeitura & 2 & $0,73 \%$ \\
\hline Outros com apenas uma reportagem & & 42 & $15,33 \%$ \\
\hline Total Geral & & 274 & $67,15 \%$ \\
\hline
\end{tabular}

Na Tabela 3, o primeiro agrupamento foi o da Prefeitura. Independentemente do cargo ou da Secretaria, todos receberam a denominação de Prefeitura. O segundo agrupamento refere-se às entidades patronais que atuam no comércio central, como Câmara dos Dirigentes Lojistas (CDL), Associação Comercial de Santos (ACS) e Sindicato do Comércio Varejista de Santos (SCVS). Ainda em relação aos empresários, 
quando estes falavam diretamente (e não representando as associações), dividimos em Empresariado (Comércio, Lazer, Porto ou Outros).

Esses agrupamentos permitiram um maior avanço nas análises, uma vez que a pulverização de atores e entidades, impossibilitava qualquer tentativa de verificar como foi formado o discurso. Dessa forma, os agrupamentos encontrados foram e deram origem à Tabela 3:

Tabela 3: Relação dos agrupamentos de Atores

\begin{tabular}{|l|c|c|}
\hline \multicolumn{1}{|c|}{ Entidade } & Total & $\begin{array}{c}\text { Total do } \\
\text { Tot }\end{array}$ \\
\hline Vereador & 126 & $45,99 \%$ \\
\hline Prefeitura & 79 & $28,83 \%$ \\
\hline CDL + ACS + SCVS & 14 & $5,11 \%$ \\
\hline Codesp & 7 & $2,55 \%$ \\
\hline Empresariado - Comércio & 7 & $2,55 \%$ \\
\hline Empresariado - Lazer & 6 & $2,19 \%$ \\
\hline Advogado & 5 & $1,82 \%$ \\
\hline Arquiteto & 5 & $1,82 \%$ \\
\hline Empresariado - Porto & 5 & $1,82 \%$ \\
\hline Empresariado - Outros & 4 & $1,46 \%$ \\
\hline Associação Centro Vivo & 3 & $1,09 \%$ \\
\hline Cidadã(o) & 3 & $1,09 \%$ \\
\hline Min.Público - prom. Meio Ambiente & 2 & $0,73 \%$ \\
\hline CDHU - Diretor & 1 & $0,36 \%$ \\
\hline Centro Português & 1 & $0,36 \%$ \\
\hline Cetesb & 1 & $0,36 \%$ \\
\hline Comitê Alegra Centro & 1 & $0,36 \%$ \\
\hline Condepasa & $\mathbf{2 7 4}$ & $\mathbf{1 0 0 , 0 0 \%}$ \\
\hline Entidade Internacional & & $0,36 \%$ \\
\hline Sindicatos - Porto & 1 & $0,36 \%$ \\
\hline USP & 1 & $0,36 \%$ \\
\hline Total Resultado & 7 \\
\hline
\end{tabular}


Como houve um claro predomínio das reportagens em que os vereadores abordavam o tema, optamos por analisar melhor esse grupo, destacando-o dos demais. Essa decisão foi útil, inclusive para entendermos melhor o papel de cada um dos demais atores.

A Tabela 4 mostra, dentre o grupo de vereadores, como foi a distribuição das reportagens:

Tabela 4: Relação dos vereadores entrevistados

\begin{tabular}{|l|c|c|c|}
\hline \multicolumn{1}{|c|}{ Ator } & Entidade & Total & $\begin{array}{c}\text { \% do } \\
\text { Total }\end{array}$ \\
\hline Mantovani Calejon (PPB) & Vereador & 28 & $22,22 \%$ \\
\hline José Antônio M. Almeida - Jama (PPS) & Vereador & 19 & $15,08 \%$ \\
\hline Adelino Rodrigues (PSB) & Vereador & 12 & $9,52 \%$ \\
\hline Cassandra Maroni (PT) & Vereador & 12 & $9,52 \%$ \\
\hline Carlos Eduardo Adegas (PL) & Vereador & 9 & $7,14 \%$ \\
\hline Odair Gonzalez (PPB) & Vereador & 8 & $6,35 \%$ \\
\hline Suely Morgado (PT) & Vereador & 7 & $5,56 \%$ \\
\hline Fausto Lopes (PFL) & Vereador & 6 & $4,76 \%$ \\
\hline Geonísio P. Aguiar (sem partido) & Vereador & 5 & $3,97 \%$ \\
\hline Manoel Constantino (PMDB) & Vereador & 5 & $3,97 \%$ \\
\hline Paulo Barbosa (PSDB) & Vereador & 3 & $2,38 \%$ \\
\hline Antonio C. Banha Joaquim (PMDB) & Vereador & 2 & $1,59 \%$ \\
\hline José Lascane (PSDB) & Vereador & 2 & $1,59 \%$ \\
\hline Marinaldo Mongon (PTB) & Vereador & 2 & $1,59 \%$ \\
\hline Professor Fabião (PSB) & Vereador & 2 & $1,59 \%$ \\
\hline Augusto Zago (PSDB) & Vereador & 1 & $0,79 \%$ \\
\hline Luzia Neófiti (PT) & Vereador & 1 & $0,79 \%$ \\
\hline Sandra Arantes do Nascimento (PDT) & Vereador & 1 & $0,79 \%$ \\
\hline Uriel Villas Boas (PCB) & & 1 & $0,79 \%$ \\
\hline Total Geral & $\mathbf{1 2 6}$ & $\mathbf{1 0 0 , 0 0 \%}$ \\
\hline
\end{tabular}

Para facilitar a compreensão, descreveremos brevemente o papel dos vereadores. Mantovani Calejon foi o relator do projeto na Câmara e, como tal, era natural ter um destaque no tema. No entanto, houve muitas reportagens com críticas por prejudicar o andamento dos trabalhos, criando sempre empecilhos nas discussões. O segundo 
vereador que mais aparece é o então Presidente da Câmara, Jama, que pelo seu cargo e pelas polêmicas criadas pela Casa, estava sempre comentando os fatos ocorridos. Em seguida, há dois vereadores da oposição e com grande “peso político”. É interessante ressaltar que a oposição votou favorável ao projeto (o que quase nunca ocorria), e na maioria das aparições, os vereadores exprimiam essa opinião e criticavam a atuação do relator, Mantovani Calejon. Logo atrás, temos o vereador Carlos Eduardo Adegas, que era o líder do governo na Câmara e como tal, opinava sobre o projeto encaminhado pelo Executivo.

Essa tabela também traz uma curiosidade. O último vereador da lista, Uriel Villas Boas, era o presidente da CEV (Comissão Especial de Vereadores) que acompanhava o Alegra Centro. No entanto, esse pouco destaque recebido por ele precisa ser relativizado, uma vez que Uriel era suplente e somente assumiu uma cadeira, quando vereador Fausto Figueira (PT) elegeu-se deputado estadual em 2002. Mesmo assim, em três anos de mandato, e como presidente da CEV foi ouvido apenas uma vez;

Após essa análise das consultas aos vereadores, há uma outra com todos os demais atores envolvidos. Na Tabela 5, podemos notar como o número de aparições do atual prefeito Papa, fica muito mais desproporcional em relação aos demais. Podemos dizer que, sem contar os vereadores, de cada 10 reportagens sobre o Alegra Centro, quase 3 delas continham o depoimento do então secretário.

Tabela 5: Relação dos atores, excluindo-se vereadores

\begin{tabular}{|l|l|c|c|}
\hline \multicolumn{1}{|c|}{ Ator } & \multicolumn{1}{|c|}{ Entidade } & Total & \% do Total \\
\hline João Paulo Tavares Papa & Prefeitura & 43 & $29,05 \%$ \\
\hline Márcio Lara & Prefeitura & 8 & $5,41 \%$ \\
\hline Beto Mansur (PPB) & Prefeitura & 7 & $4,73 \%$ \\
\hline Pedro Mahfuz Júnior & CDL + ACS + SCVS & 6 & $4,05 \%$ \\
\hline Amadeu Lopes Lousada & CDL + ACS + SCVS & 5 & $3,38 \%$ \\
\hline Nobel Soares & Advogado & 4 & $2,70 \%$ \\
\hline Antonio Carlos Gonçalves & Prefeitura & 3 & $2,03 \%$ \\
\hline Débora Blanco & Prefeitura & 3 & $2,03 \%$ \\
\hline Eduardo Carvalhaes Júnior & Associação Centro Vivo & 3 & $2,03 \%$ \\
\hline
\end{tabular}




\begin{tabular}{|l|l|c|c|}
\hline Fernando Vianna & Codesp & 3 & $2,03 \%$ \\
\hline Luiz Dias Guimarães & Prefeitura & 3 & $2,03 \%$ \\
\hline Assesoria de Imprensa da Seplan & Prefeitura & 2 & $1,35 \%$ \\
\hline Assessoria de Imprensa da Codesp & Codesp & 2 & $1,35 \%$ \\
\hline Claudio Abdalla & Arquiteto & 2 & $1,35 \%$ \\
\hline Cláudio Ciorlia Denipoti & Empresariado - Outros & 2 & $1,35 \%$ \\
\hline Daury de Paula Júnior & Ministério Público & 2 & $1,35 \%$ \\
\hline Júlio Eduardo dos Santos & Prefeitura & 2 & $1,35 \%$ \\
\hline Luiz Carlos Santini Mello & Prefeitura & 2 & $1,35 \%$ \\
\hline Ney Caldato & Arquiteto & 2 & $1,35 \%$ \\
\hline Seplan - sem interlocutor & Prefeitura & 2 & $1,35 \%$ \\
\hline Tom Barboza & Prefeitura & 40 & $27,03 \%$ \\
\hline Outros com uma ocorrência & & $\mathbf{1 4 8}$ & $\mathbf{1 0 0 , 0 0 \%}$ \\
\hline Total Geral & & & \\
\hline
\end{tabular}

Com esses dados, é possível questionar o baixo aparecimento dos empresários já instalados ou que pretendiam se instalar na região central. Mesmo a autoridade portuária (CODESP) que deve estar diretamente envolvida em qualquer projeto urbanístico na região central (muito próxima ao Porto), foi pouquíssimas vezes citada. Se nem os membros da sociedade civil santista que construíram o Alegra Centro mereceram a devida ênfase pela cobertura do jornal, de acordo com os trabalhos anteriores, os atores marginais do processo, associados a questão social do programa Associação dos Cortiços do Centro - não figuram em nenhuma matéria.

\section{A Cultura e o Centro}

Alinhado com o pensamento de que a transformação do Centro virá com o desenvolvimento de atividades lucrativas e não com assistência social (Porter apud Hiernaux-Nicolas, 2006), os promotores dessa política pública pensam em alternativas para fortalecer o turismo na região, como meio de alavancar esse processo. Para isso, duas dimensões serão criadas: a constituição do espaço do centro histórico e a exploração da cultura enquanto negócio, por meio dos patrimônios históricos. 
Ao atribuir um valor histórico a toda uma área específica da cidade, torna-se homogênea uma região que é diversa - e conflitante. Como vimos, o Centro de Santos abriga, em conjunto, setores econômicos relevantes, sedes das instituições políticas, comércio popular e os cortiços. O discurso pró-revitalização, então, irá colocar os cortiços como símbolo da degradação urbana da região, o que justificaria a intervenção. Esta, por sua vez, tratará de expandir a parte valorizada do Centro, em direção aos cortiços. O objeto é o espaço, e não quem habita o espaço. Em outras palavras, as pessoas - moradoras - da região são alijadas da transformação, revitalização:

Esses centros históricos foram progressivamente institucionalizados. E não apenas: este espaço torna-se espaço de referência das medidas de proteção de patrimônio, mas também (...) um sub-espaço particular a ser tomado em conta na gestão urbana cotidiana. (...) A progressiva constituição de um campo particular de intervenção permitiu reunir diferentes tipos de espaço (...), [o que] tem uma eficácia dupla nos discursos e nas representações do centro. De uma parte, toda ação em favor do centro histórico pode ser apresentada como uma ação contra o declínio urbano: a injução "salvar o centro histórico" se aplica indiferentemente sobre o conjunto do centro; por outro lado, a imagem da "vecinidad" [termo mexicano para designar as moradias coletivas, semelhante aos cortiços brasileiros], do palácio do governador, do museu e do banco estão unidas por um destino comum. As dinâmicas de refinamento comercial relativas ao centro comercial valorizado podem ser apresentadas, a partir daí, como uma conquista das políticas de retorno ao centro. No entanto, em algumas cidades, observa-se uma extensão do centro comercial valorizado, e o desenvolvimento de projetos públicos de restauração de imóveis para serviços públicos que contribuem para a expansão da parte valorizada do centro histórico (Hiernaux-Nicolas, 2006, p.204-5).

Essa construção sobre “o que é o centro histórico” irá, ainda, segundo o autor, colaborar na designação dos bairros populares como espaços degradados em relação à grandeza histórica dos patrimônios, bem como à parte valorizada dos centros, o que exclui dos processos os moradores da região. Nesse sentido, pode-se observar uma instrumentalização da questão do patrimônio:

Tudo indica, e os interesses econômicos estão confirmando, que hoje preserva-se em atendimento às exigências do turismo (...). O turismo nasceu em volta de bens culturais paisagísticos e arquitetônicos preservados, e hoje, cada vez mais, vai 
exigindo a criação de mais cenários, de mais exotismos, provocando quadros artificiais, inclusive (Lemos, 1987, p.30).

O papel desses imóveis seria o de “âncoras culturais” (Kara-José, 2007), ou seja, o de disparar a "revitalização" no seu entorno através da atração de grupos sociais de maior renda que deixaram de freqüentar os centros. Em Santos, esses imóveis podem ser ilustrados pelo imóvel da Bolsa do Café e o Museu do Café que ali foi constituído - bem como toda a transformação ocorrida na Rua XV de Novembro, atual símbolo do potencial da “revitalização” na cidade - e o Teatro Coliseu - hoje palco para espetáculos voltados para públicos de alta renda.

Esses dois equipamentos estão ligados, histórica e politicamente, com a Santos do século passado. O café, como vimos, além de transformar a cidade do ponto de vista urbanístico, também consolidou uma elite local (Lanna, 1996). A reurbanização higienista, que se viu à época, tratou de construir equipamentos como o Teatro Coliseu para que fossem símbolos da riqueza dessa elite. Ao mesmo tempo, o uso desses equipamentos esteve restrito a esses grupos.

A classe dominante, quase sempre, tem seu prestígio herdado e, por isso, gosta de preservar e recuperar os testemunhos materiais de seus antepassados numa demonstração algo romântica ou saudosista, constituindo tudo isso de afirmação elitista. Vive-se do passado, das glórias dos outros tempos. A preservação de bens culturais para ela constitui a obrigação de manter viva a memória dos avós. (Lemos, 1987, p.31)

Deve-se levar em consideração que a política de "revitalização" do centro de Santos é diretamente influenciada por grupos como os empresários do café, os comerciantes locais e a associação dos construtores civil. Os dois primeiros se consolidaram como elite local ao início do século passado; o último, lucra com a valorização imobiliária da região central.

Dessa forma, não se pode esquecer que, apesar dos discursos apresentados de "resgate da história do povo santista”, ou ainda “preservação do patrimônio histórico e cultural da cidade”, existe um componente político, muitas vezes ocultados, nessas intervenções.

[Trata-se de] um processo em que o mote "valorização da cultura" surge como estratégia de despolitização da atuação do Estado no espaço urbano, já que, embora não se fale em política ou plano urbanístico, as conseqüências esperadas com a 
implantação dos programas são de transformação socioespacial de um território da cidade (Kara-José, 2007, p. 243).

É dessa maneira que a política pública buscará se legitimar: como resgate e preservação da memória santista e, assim, um movimento pelo bem coletivo. Pollack (1992) demonstra que a memória é, ao mesmo tempo, “seletiva”, “um fenômeno construído” e “elemento constituinte do sentimento de identidade” e que, por isso, é uma questão constantemente em disputa entre grupos sociais. O que o autor chama de “trabalho de enquadramento da memória”, está intimamente relacionado ao processo em curso na cidade:

A memória, essa operação coletiva dos acontecimentos e das interpretações do passado que se quer salvaguardar, se integra, como vimos, em tentativas mais ou menos conscientes de definir e de reforçar sentimentos de pertencimento e fronteiras sociais entre coletividades de tamanhos diferentes: partidos, sindicatos, igrejas, aldeias, regiões, clãs, famílias, nações etc. A referência ao passado serve para manter a coesão dos grupos e das instituições que compõem uma sociedade, para definir seu lugar respectivo, sua complementariedade, mas também as oposições irredutíveis (Pollack, 1989, p.3-15).

E é justamente esse movimento que consegue contornar o conflito - ou ainda, deslegitimá-lo. É como se ele não existisse, porque não haveria razão de ser contra o "bem de todos”. Mais que isso, um grupo social sai fortalecido desse processo, principalmente do ponto de vista político. Ainda que "todo trabalho de enquadramento de uma memória de grupo tem limites, pois ela não pode ser construída arbitrariamente” (Pollack, 1989), todo o arranjo para a construção desse consenso vai, gradativamente, consolidando-o. Negando-se, repetidamente, a participação dos moradores dos cortiços nos rumos da cidade.

\section{Considerações Finais}

Por se tratar de um fenômeno tão recente e, também, por seus arranjos estarem, ainda, em fase de consolidação, é impossível dizer de maneira absoluta os rumos que a política pública de “revitalização” do centro de Santos irá tomar.

De acordo com os resultados apresentados nesta pesquisa, o caminho mais provável é que os empresários locais continuem pleiteando novos benefícios fiscais, enquanto os moradores dos cortiços tendem a prosseguir marginalizados - ou invisíveis - de todo esse processo - no âmbito da mídia e da política pública. 
Entretanto, apesar dessa tendência, existe, sim, a possibilidade de que um arranjo político

maior seja formado, a fim de englobar, também, a questão social. Nesse caso, como vimos, os instrumentos de construção do consenso e, em conseqüência, de legitimação dessa intervenção, já estão colocados.

Artigo recebido em: 25/10/2006 e aceito em 12/ 12 /2006.

1 A Ciutat Vella de Barceloa: renovação ou gentrificação in De Volta à Cidade, Bidou-Zachariasen (coord), 2006.

1 A reapropriação de bairros da Cidade do México pelas classes médias: em direção a uma gentrificação? in De Volta à Cidade, Bidou-Zachariasen (coord), 2006.

1 A reapropriação do patrimônio simbólico do centro de Nápoles in De Volta à Cidade, Bidou-Zachariasen (coord), 2006.

$1 \quad$ Na gestão de Oswaldo Justo (PMDB), eleito em 1984, foi realizada a desapropriação da Casa da Frontaria Azulejada. Telma de Souza (1989-1992), do PT, restaura o imóvel, completando, assim, a ação anterior, além de criar a Fundação Arquivo e Memória de Santos e o Conselho de Defesa do Patrimônio Cultural de Santos. David Capistrano (1993-1996), também do PT, implementa o projeto "Cores da Cidade”, em parceria com a Fundação Roberto Marinho, com o objetivo de recuperar a fachadas dos edifícios históricos, entre eles, o Outeiro de Santa Catarina; nesta gestão, ainda, surge o movimento de opinião chamado Centro Vivo, formado por empresário locais e cujos objetivos eram: evitar a saída de empresas do Centro, incentivar pessoas de fora da cidade a visitar o Centro e manter as fachadas históricas, por meio de isenção da taxa de obra e do IPTU como benefício. Esse movimento irá apoiar o prefeito seguinte, Beto Mansur.

1 (Re)investir nos espaços centrais das cidades mexicanas in De Volta à Cidade, Bidou-Zachariasen (coord), 2006.

1 A página na Internet da Secretaria de Habitação do Estado de São Paulo informa que existem 194 unidades habitacionais programadas por meio do PAC para a cidade de Santos.

$1 \quad$ Números fornecidos no site de A Tribuna (www.atribuna.com.br).

1 Disponível em: http://www.unb.br/fac/comunicacaoepolitica/AlessandraWeltman2000.pdf

1 A própria Rede Globo já chegou a ser alvo de protestos da população quando não noticiava os comícios da campanha das Diretas-Já, até chegar a um ponto em que pela própria pressão popular, foi obrigada a noticiar o acontecimento.

1 Esta discussão não é nova e além de Bagdikian, Chomsky, Key, e Sartori, outros tantos tratam deste assunto.

1 Como exemplo, podemos falar dos jornais Folha de São Paulo e O Estado de São Paulo, ambos situados na cidade de São Paulo e que pertencem às famílias Frias e Mesquita, respectivamente. Do mesmo modo, a família Marinho é proprietária do periódico O Globo, no Rio de Janeiro e, mais ainda, das Organizações Globo, que se constituem no maior conglomerado de comunicações do Brasil. 


\section{Referências Bibliográficas}

ALDÉ, A. e LATTMAN-WELTMAN, F. O MST na TV: sublimação do político, moralismo e crônica cotidiana do nosso "estado de natureza”. Disponível em: http://www.unb.br/fac/comunicacaoepolitica/AlessandraWeltman2000.pdf

BAGDIKIAN, B H. O Monopólio da Mídia. São Paulo; Scritta, 1ª edição, 1993.

BARBALHO, A. Estado, mídia e identidade: políticas de cultura no Nordeste contemporâneo. Revista Alceu, v. 4, n.8, p. 156-167, jan./jun. 2004.

BIDOU-ZACHARIASEN, C. (coord) De Volta à Cidade. São Paulo; Annablume. 2006.

BOURDIEU, P. Sobre a Televisão. Rio de Janeiro; Jorge Zahar Editor, 1ª edição, 1997.

CHALHOUB, S. Classes perigosas in Trabalhadores, nº 6. Campinas, 1990, p. 2-22.

. Cidade Febril: cortiços e epidemias na Corte imperial. São Paulo; Companhia das Letras, 1996.

COBB, R. W. and ELDER, C. D. Issues and agendas. In: THEODOULOU, S. and CAHN, M. A. Public policy: the essential readings. Upper Saddle River, NJ, Prentice Hall, 1995.

FUKS, M. Definição da agenda, debate público e problemas sociais: uma perspectiva

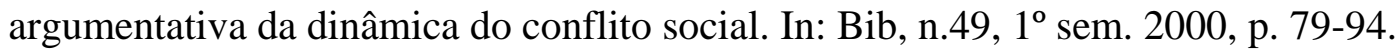

GITAHY, M. L. Porto de Santos - 1888-1908 in Libertários no Brasil, PRADO, A. A. (org.). São Paulo: Editora Brasiliense, 1986.

KARA-JOSÉ, B. Políticas Culturais e Negócios Urbanos: a instrumentalização da Cultura na Revitalização do Centro de São Paulo 1975-2000. São Paulo; Annablume, 2007.

KINGDON, J. W. Agendas, Alternatives and Public Policies. United States of America: Addison-Wesley Longman, 1995.

LANNA, A. L. D. Uma Cidade na Transição - Santos: 1870-1913. São Paulo; Editora Hucitec. 1996.

LEMOS, C. A. O que é Patrimônio Histórico? São Paulo; Brasiliense, 1987 
OLIVEIRA, F. de. Aproximações ao Enigma: o que é Desenvolvimento Local? in Novos Contornos da gestão local: conceitos em construção. CACCIA-BAVA, S., PAULICS, V. e SPINK, P. (orgs.) São Paulo; Polis; Programa Gestão Pública e Cidadania/FGV-EAESP, 2002.

POLLACK, M. Memória, Esquecimento, Silêncio in Estudos Históricos, Rio de Janeiro, vol. 2, $\mathrm{n}^{\circ} 3,1989, \mathrm{p} .3-15$.

Memória e Identidade Social in Estudos Históricos, Rio de Janeiro, vol.5, nº 10, 1992, p.200-212.

PORTER, M. The competitive advantage of inner cities in Harvard Business Review, Boston: Harvard University, mai-jun, 1995, p. 55-71.

PORTO, M. Jornal Nacional, antes e depois da saída de Cid Moreira. Trabalho apresentado no $22^{\circ}$ Congresso Brasileiro de ciências da Comunicação. Rio de Janeiro. 03 a 09/09/99.

SANTOS, M. B. P. dos. Imprensa e Telejornal: visões políticas de Santos. Dissertação de mestrado apresentado ao Programas de Estudos Pós-graduados em Ciências Sociais da PUC-SP. São Paulo, 2003.

SIMÕES JR., J. G. Revitalizações de Centros Urbanos. São Paulo. Polis. 1994.

SMITH, N. The New Urban Frontier: Gentrification and the Revanchist City. New York. Routledge. 1996.

TRAQUINA, N. O Estudo do Jornalismo no Século XX. São Leopoldo, Unisinos, 2001. WOLF, M. Teorias da Comunicação. Editorial Presença, Portugal, 1987. 